\title{
Effect of suramin on myotoxicity of some crotalid snake venoms
}

E.Z. Arruda, N.M.V. Silva,

R.A.M. Moraes and P.A. Melo
Departamento de Farmacologia Básica e Clínica, Instituto de Ciências Biomédicas, Centro de Ciências da Saúde, Universidade Federal do Rio de Janeiro, Rio de Janeiro, RJ, Brasil

\section{Correspondence \\ P.A. Melo \\ Departamento de Farmacologia \\ Básica e Clínica \\ Instituto de Ciências Biomédicas \\ CCS, UFRJ \\ 21941-590 Rio de Janeiro, RJ \\ Brasil \\ Fax: +55-21-2280-4694 \\ E-mail: pamelo@farmaco.ufrj.br}

Research supported by CNPq (PIBIC),

CAPES, PRONEX, Fundação

Universitária José Bonifácio

(FUJB-UFRJ) and FAPERJ.

Received April 18, 2001

Accepted April 19, 2002

\section{Abstract}

We investigated the protective effect of suramin, an enzyme inhibitor and an uncoupler of $\mathrm{G}$ protein from receptors, on the myotoxic activity in mice of different crotalid snake venoms (A.c. laticinctus, C.v. viridis, C.d. terrificus, B. jararacussu, B. moojeni, B. alternatus, B. jararaca, $L$. muta). Myotoxicity was evaluated in vivo by injecting im the venoms $(0.5$ or $1.0 \mathrm{mg} / \mathrm{kg})$ dissolved in physiological saline solution $(0.1 \mathrm{ml})$ and measuring plasma creatine kinase $(\mathrm{CK})$ activity. Two experimental approaches were used in mice $(\mathrm{N}=5$ for each group). In protocol A, $1 \mathrm{mg}$ of each venom was incubated with $1.0 \mathrm{mg}$ suramin $\left(15 \mathrm{~min}, 37^{\circ} \mathrm{C}\right.$, in vitro $)$, and then injected im into the mice at a dose of $1.0 \mathrm{mg} / \mathrm{kg}$ (in vivo). In protocol B, venoms, $1.0 \mathrm{mg} / \mathrm{kg}$, were injected $\mathrm{im} 15 \mathrm{~min}$ prior to suramin $(1.0 \mathrm{mg} / \mathrm{kg}, i v)$. Before and $2 \mathrm{~h}$ after the $i m$ injection blood was collected by orbital puncture. Plasma was separated and stored at $4^{\circ} \mathrm{C}$ for determination of CK activity using a diagnostic kit from Sigma. Preincubation of some venoms (C.v. viridis, A.c. laticinctus, C.d.terrificus and B. jararacussu) with suramin reduced (37-76\%) the increase in plasma $C K$, except for B. alternatus, $B$. jararaca or $L$. muta venoms. Injection of suramin after the venom partially protected (34-51\%) against the myotoxicity of $B$. jararacussu, A.c. laticinctus and C.d. terrificus venom, and did not protect against C.v. viridis, L. muta, B. moojeni, B. alternatus or B. jararaca venoms. These results show that suramin has an antimyotoxic effect against some, but not all the North and South American crotalid snake venoms studied here.

Myonecrosis can be a significant consequence of poisoning by snake venom components named myotoxins, and many antivenins are ineffective in antagonizing the activity of these myotoxins (1-4). We have previously shown that heparin and other polyanions inhibit the increase of creatine kinase (CK) release induced by crotalid venoms in mice (5-8). We ascribed this antagonism to the formation of acid-base complexes between the basic myotoxins of the
Key words - Snake venom - Myotoxicity

- Creatine kinase

- Suramin ........................

venoms and the polyanion compounds. There are reports suggesting that some heparinoids exhibit various biological functions $(9,10)$ and among them, suramin, one of the oldest heparinoids, represents an important target molecule $(11,12)$. Suramin is a polysulfonated naphthylamine-amine-benzamide derivative (Figure 1) that has been widely used for more than fifty years in the treatment of onchocerciasis and trypanosomiasis (12-14). There are several reports showing that suramin has 
anti-enzymatic activity by binding basic proteins and it also inhibits the coupling of various metabotropic autonomic receptors to the $\mathrm{G}$ proteins. Among the targets, are the $G$ protein subunits in which suramin inhibits guanosine diphosphate release $(13,14)$. Suramin blocks cell surface binding of various growth factors and increases tissue glycosaminoglycans (12-14). There are also studies showing that suramin can inhibit the neurotoxic effect of ß-bungarotoxin and partially inhibit some pharmacological effects of Cerastes vipera venom $(15,16)$.

In the present study we investigated the antagonism or protection of the myotoxic effect of some North and South American snake venoms by this polysulfated substance. Experiments were performed with Bothrops jararacussu and $B$. jararaca venoms obtained from Instituto Vital-Brazil (Niterói, RJ, Brazil), B. alternatus, B. moojeni, and Crotalus durissus terrificus venoms from the Instituto Butantan (São Paulo, SP, Brazil), whereas $C$. viridis viridis (prairie rattlesnake) and Agkistrodon contortrix laticinctus (broad-banded copperhead) venoms were obtained from the Venom Research Laboratory (Oklahoma State University, Stillwater, OK, USA). Lachesis muta venom and suramin were purchased from Sigma (St. Louis, MO, USA). All other compounds were of analytical grade.

Venoms, whose quantity is reported as mg protein and whose protein concentration was estimated as described by Fuly et al.

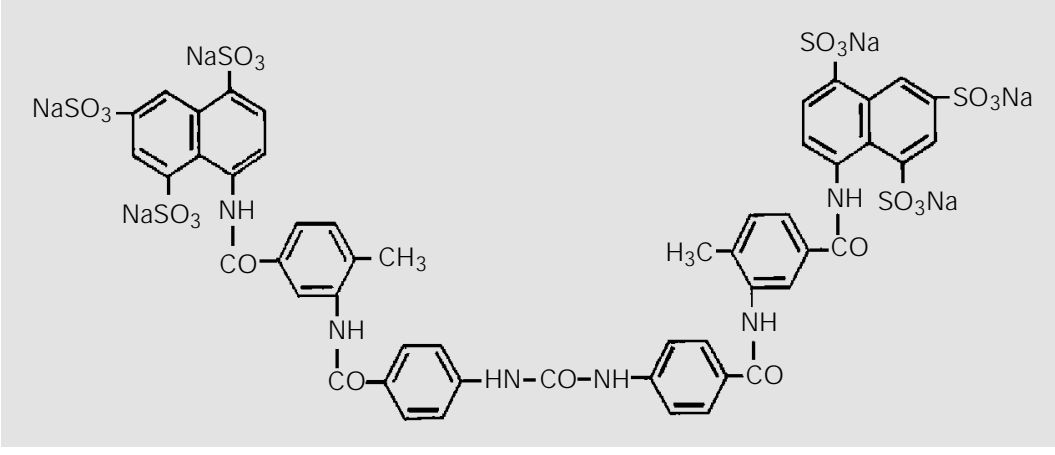

Figure 1. Structure of suramin, a polysulfonated naphthylurea (molecular weight 1429).
(17), were dissolved in physiological saline solution (PSS; $0.1 \mathrm{ml}$ ) and injected im into the thigh of Swiss mice (20-25 g). Venom was injected at a dose of $1.0 \mathrm{mg} / \mathrm{kg}$, except for C.d. terrificus venom or B. jararaca, which was injected at the dose of $0.5 \mathrm{mg} / \mathrm{kg}$. Previous studies showed that im injection of $0.1 \mathrm{ml}$ PSS has no effect on plasma CK levels (5-8).

Two experimental protocols were used. In protocol A, $1.0 \mathrm{mg} / \mathrm{ml}$ of suramin and 0.5 $1.0 \mathrm{mg}$ venom $/ \mathrm{ml}$ were incubated together for $15 \mathrm{~min}$ at $37^{\circ} \mathrm{C}$ (in vitro), and then injected $\mathrm{im}, 1 \mathrm{mg}$ venom $/ \mathrm{kg}$, into each animal (in vivo). In protocol $\mathrm{B}$, each venom was administered $\mathrm{im}$ to the animals $15 \mathrm{~min}$ before the intravenous injection of suramin $(1.0 \mathrm{mg} / \mathrm{kg})$. In both protocols the final volume of venom injected, alone or plus suramin, was $0.1 \mathrm{ml}$. The venom doses were selected based on previous studies (5-8). The animals were lightly anesthetized with diethyl ether immediately before and $2 \mathrm{~h}$ after venom injection for blood collection according to the guidelines for care and use of laboratory animals (18). Plasma was separated by centrifugation and stored at $4^{\circ} \mathrm{C}$ for subsequent determination of $\mathrm{CK}$ activity. The procedure for the measurement of CK activity has been described previously $(1,5-8)$. Enzyme activity is reported as international units per liter (U/l), where $1 \mathrm{U}$ is the amount that catalyzes the transformation of $1 \mu \mathrm{mol}$ of substrate at $25^{\circ} \mathrm{C}$.

Figure 2 shows that im injections of all crotalid crude venoms induced a significant increase in plasma CK activity compared to PSS. B. jararacussu venom injection increased CK levels from $71.16 \pm 7.44$ (mean \pm SEM, $\mathrm{N}=5)$ to $5384.8 \pm 187.4 \mathrm{U} / \mathrm{l}(\mathrm{N}=5)$ at $2 \mathrm{~h}$. For all the other venoms intermediate values were obtained. Preincubation of the venom with suramin significantly $(\mathrm{P}<0.05)$ inhibited the increase in plasma CK activity induced by B. jararacussu, B. moojeni, C.d. terrificus, C.v. viridis and A.c. laticinctus venoms. However, suramin did not offer 
protection against the myotoxicity of $B$. alternatus, L. muta (Figure 2) or B. jararaca venom (data not shown). Protocol B showed that suramin significantly $(\mathrm{P}<0.05)$ inhibited the increase in plasma $\mathrm{CK}$ activity induced by B. jararacussu, C.d. terrificus and A.c. laticinctus venoms and did not antagonize the myotoxicity of B. alternatus, B. moojeni, C.v. viridis, L. muta (Figure 2) or B. jararaca venom (data not shown). It is interesting to note that, in protocol $\mathrm{B}$, suramin was less effective in antagonizing the myotoxic effect of some venoms which present very active hemorrhagic toxins in their composition (1820).

In summary, these data show that suramin protects against the myotoxic effect of some (B. jararacussu, C.d. terrificus and A.c. laticinctus), but not all (C.v. viridis, B. moojeni and $L$. muta) venoms in both protocols. Some closely related venoms (B. alternatus and $B$. jararaca) sometimes gave opposite results. The present results extend previous observations showing that polysulfated substances neutralize the toxicity of some crotalid venoms, which have been reported to contain basic myotoxic phospholipases $\mathrm{A}_{2}\left(\mathrm{PLA}_{2}\right.$; $2,4,8,18)$. These myotoxic PLA $_{2}$ present in some crotalid venoms are either Asp- 49 catalytically active variants or Lys-49, enzymatically inactive homologues $(4,18)$. However, suramin offered no protection against the myotoxicity of Bothrops venoms (B. alternatus or $B$. jararaca) whose study did not reveal basic myotoxic $\mathrm{PLA}_{2}$ (18). Like heparin, suramin did not protect against the myotoxicity of $L$. muta venom, in agreement with our previous data (17). These results indicate that suramin has a significant antivenom effect against some crotalid snake venoms. It partially reproduces the antimyotoxic effect previously described for other polysulfated substances $(5,6,8)$ and deserves

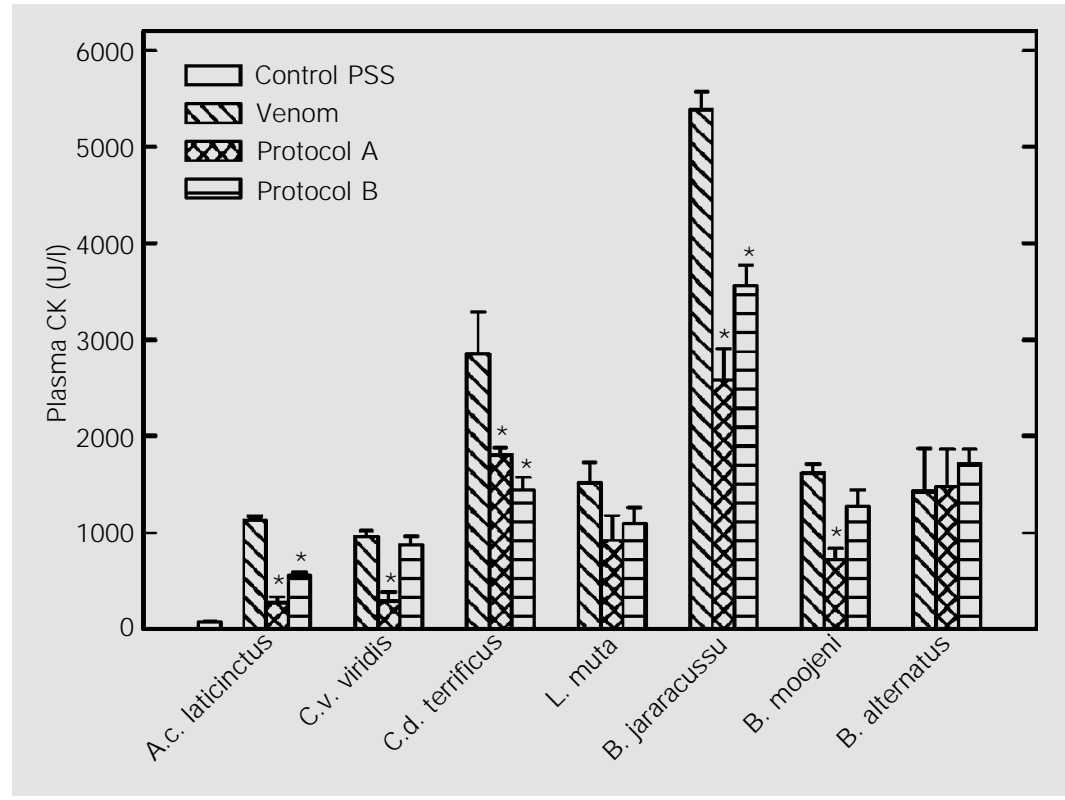

Figure 2. Effect of intramuscular injection of crotalid venoms on plasma creatine kinase (CK) activity and effect of treatment with suramin. Suramin $(1.0 \mathrm{mg} / \mathrm{kg})$ was administered according to two protocols: protocol A, preincubation in vitro with each venom; protocol B, $15 \mathrm{~min}$ iv administration of suramin after im injection of venom. Plasma CK activity of the physiological saline solution (PSS) control group was $71.16 \pm 7.44 \mathrm{U} / \mathrm{l}(\mathrm{N}=5)$. The animals received the venom at the dose of $1 \mathrm{mg} / \mathrm{kg}$, except for a group that received C.d. terificus crude venom at the dose of $0.5 \mathrm{mg} / \mathrm{kg}$. The values reported are means $\pm \mathrm{SEM} . * \mathrm{P}<0.05$ for the difference between the control (venom alone) and the values for each of the two protocols for suramin treatment (ANOVA).

further study to evaluate its antimyotoxic activity and therapeutic potential as an antivenin.

\section{Acknowledgments}

We thank Dr. Yasco Aracava for a careful reading of the manuscript. The authors also wish to thank Dr. Anibal Melgarejo from Instituto Vital Brazil for providing $B$. jararacussu and B. jararaca venoms, Dr. Charlotte L. Ownby for providing the two North American venoms, $C$. viridis viridis and A. contortrix laticinctus, and Dr. Edson Xavier Albuquerque for providing the suramin. 


\section{References}

1. Mebs D, Ehrenfeld $M \&$ Samejima $Y$ (1983). Local necrotizing effect of snake venoms on skin and muscle: relationship to serum creatine kinase. Toxicon, 21: 393-404.

2. Mebs D \& Ownby CL (1990). Myotoxic components of snake venoms: their biochemical and biological activities. Pharmacology and Therapeutics, 48: 223-236.

3. Lomonte B, Gutiérrez J M, Rojas G \& Calderon L (1991). Quantitation by enzyme-immunoassay of antibodies against Bothrops myotoxins in four commerciallyavailable antivenoms. Toxicon, 29: 695702.

4. Ownby $\mathrm{CL}$, Selistre de Araujo HS, White SP \& Fletcher J E (1999). Lysine 49 phospholipase $A_{2}$ proteins. Toxicon, 37: 441445.

5. Melo PA \& Suarez-Kurtz G (1988). Release of sarcoplasmic enzymes from skeletal muscle by Bothrops jararacussu venom: antagonism by heparin and by the serum of South American marsupials. Toxicon, 26: 87-95.

6. Melo PA, Homsi-Brandemburgo MI, Giglio J R \& Suarez-Kurtz G (1993). Antagonism of the myotoxic effects of Bothrops jararacussu venom and bothropstoxin by polyanions. Toxicon, 31: 285-291.

7. Melo PA, Nascimento MC, Mors WB \& Suarez-Kurtz G (1994). Inhibition of the myotoxic and hemorrhagic activities of crotalid venoms by Eclipta prostrata (Asteraceae) extracts and constituents. Toxicon, 32: 595-603.

8. Melo PA \& Ownby CL (1999). Ability of wedelolactone, heparin and para-bromo- phenacyl bromide to antagonize the myotoxic effects of two crotaline venoms and their PLA $\mathrm{P}_{2}$ myotoxins. Toxicon, 37: 199-215.

9. Nader HB, Chavante SF, Dos Santos EA, Oliveira FW, De-Paiva J F, J eronimo SBM, Medeiros GF, Abreu LRD, Leite EL, DeSouza-Filho J F, Castro RAB, Toma L, Tersariol ILS, Porcionato MA \& Dietrich CP (1999). Heparan sulfates and heparins: similar compounds performing the same functions in vertebrates and invertebrates. Brazilian J oumal of Medical and Biological Research, 32: 529-538.

10. Gunay NS \& Linhardt RJ (1999). Heparinoids: Structure, biological activities and therapeutic applications. Planta Medica, 65: 301-306.

11. Ruey-Ruey $\mathrm{CH}$, Dehaven RN, Cheung $\mathrm{AH}$, Diehl RE, Dixon RAF \& Strader CD (1989). Identification of allosteric antagonists of receptor-guanine nucleotide binding protein interactions. Molecular Pharmacology, 37: 304-310.

12. Nakajima $M$, Dechavigny $A$, J ohnson $C E$, Hamada J , Stein CA \& Nicolson GL (1999). Suramin, a potent inhibitor of melanoma heparanase and invasion. J ournal of Biological Chemistry, 266: 9661-9666.

13. Freissmuth $M$, Boehm S, Beindl $W$, Nickel $P$, Ljzerman AP, Hohnegger $M \&$ Nanoff $C$ (1996). Suramin analogues as subtypeselective $\mathrm{G}$ protein inhibitors. Molecular Pharmacology, 49: 602-611.

14. Freissmuth $M$, Waldhoer $M$, BofillCardona E \& Nanoff C (1999). G protein antagonists. Trends in Pharmacological Sciences, 20: 237-245.
15. Lin-Shiau SY \& Lin MJ (1999). Suramin inhibits the toxic effects of presynaptic neurotoxins at the motor nerve terminals. European J ournal of Pharmacology, 382: 75-80.

16. Alzahaby M, Rowan EG, Young LC, AlZahaby AS, Abu-Sinna G \& Harvey AL (1995). Some pharmacological studies on the effects of Cerastes vipera (Sahara sand viper) snake venom. Toxicon, 33: 1299-1311.

17. Fuly AL, Calil-Elias S, Zingali RB, Guimarães J A \& Melo PA (2000). Myotoxic activity of an acidic phospholipase $A_{2}$ isolated from Lachesis muta (Bushmaster) snake venom. Toxicon, 38: 961-972.

18. Mass J, Heling W \& Seeger K (1997). Anesthesia of experimental animals. In: Vogel HG \& Vogel WH (Editors), Drug Discovery and Evaluation. Pharmacological Assays. Springer-Verlag, Berlin, Heidelberg, Germany, 732-738.

19. Adrião-Escarso $S H$, Soares $A M$, Rodrigues VM, Angulo Y, Díaz C, Lomonte B, Gutiérrez J M \& Giglio J R (2000). Myotoxic phospholipases $A_{2}$ in Bothrops snake venoms: Effect of chemical modifications on the enzymatic and pharmacological properties of bothropstoxins from B. jararacussu. Biochimie, 82: 755-763.

20. Ownby $\mathrm{CL}$, Colberg TR \& White SP (1997). Isolation, characterization and crystallization of a phospholipase A2 myotoxin from the venom of the prairie rattlesnake (Crotalus viridis viridis). Toxicon, 35: 111-124. 